\title{
Política democrática radical y feminismo
}

\section{Radical democratic politics and feminism}

\author{
Soledad Martínez Labrín \\ Universidad del Bío-Bío, Chile \\ cmartine@ubiobio.cl
}

\begin{abstract}
Resumen
Abstract

En este artículo presento una reflexión sobre el In the article I present a reflection around the radical proyecto democrático radical de Chantal Mouffe y democratic project proposed by Chantal Mouffe and Ernesto Laclau. Específicamente, examino su Ernesto Laclau. Specifically, I examine the application aplicación en el contexto de los "nuevos movimientos of the project in the context of the "new social sociales" y, en especial, del movimiento feminista. movements" and especially, of feminist movement. I Planteo la necesidad de poner atención al state the need of drawing attention to universalism and universalismo y al esencialismo como principales essentialism as the main obstacles to generate a obstáculos para generar un colectivo sin márgenes. Sin collective proposal without margins. Nevertheless, embargo, queda la duda respecto de la posibilidad o no doubts remind about the possibility of building up a de construir un feminismo a la medida de la democracia feminism tailored by the radical democratic project, in a radical, en un punto en el que la acción política de stage in which the political action of such a movement dicho movimiento está categorialmente cerrada $\mathrm{y}$ is characterized by categories that are closed and cristalizada. crystallized.

Palabras clave: Democracia radical; Feminismo; Keywords: Radical democracy; Feminism; Social Movimientos sociales movements
\end{abstract}

Podríamos decir que estamos asistiendo a la progresiva desnaturalización y desuniversalización de las identidades y de las luchas políticas. La política que en los sesenta se caracterizó por una lucha de grupos identitarios que rompían la tradición marxista de la clase como exclusiva unidad de análisis, ahora es insuficiente para teóricas y políticas. Para la política feminista, sin embargo, esta tendencia no es tan clara aún. El esencialismo y la identificación identitaria han sido una bandera de lucha y un argumento de fuerza para la propagación del feminismo al campo de lo legítimo y lo público. Así, la esencia natural del ser mujer ha sido la justificación tanto para la integración reformista como para el separatismo radical ${ }^{1}$. No sólo la radical diferencia con los hombres ha sido

\footnotetext{
${ }^{1}$ Es importante rescatar, sin embargo, la multiplicidad de posiciones que los diversos feminismos han construído respecto de la categoría mujer. La sujeta no ha sido siempre concebida desde una óptica escencialista ni universalista, de hecho, los feminismos han liderado la crítica al universalismo y al esencialismo como metanarrativas hegemónicas de producción de poder.
} 
subrayada en nombre de las esencias, sino también la traición por parte de algunos grupos lésbicos cuya emulación de las características de los hombres es vista como una negación de su propia naturaleza (Preciado, 2002). El esencialismo, a la vez que el universalismo, también han sido, quizás sin querer, la causa de la negligencia de las feministas a cualquier categoría que no fuera el género o el sexo, tales como la clase, raza, edad, y así, durante mucho tiempo, el feminismo fue (y gran parte de éste aún lo es) ciego a las diferencias entre mujeres; ya que la identidad en la vida cotidiana no puede homologarse a la experiencia. De este modo, retrospectivamente, el feminismo (si es posible decirlo en singular) fue el movimiento de unas pocas en nombre de todas y probablemente junto con sus conquistas, que no fueron pocas, contribuyó a silenciar e invisibilizar aún más las diferencias y las causas nacidas desde estas diferencias (Hooks, 1984). La idea de un sujeto "transparente y racional" (Mouffe, 1999:109) autor (o autora en el caso del feminismo) por excelencia es, de este modo, incompatible con la idea de una democracia de la diversidad y la comunidad. El esencialismo, según Chantal Mouffe (1999) no es un problema porque no sea progresista, sino que su deficiencia radica en la imposibilidad de generar un proyecto político en el que se articulen luchas diferentes, respondientes a diferentes modelos de opresión.

Mouffe nos plantea en su proyecto, que la deconstrucción de las identidades esenciales es condición necesaria para una democracia radical. El problema aquí es hacer una distinción entre las identidades a deconstruir (esenciales) y las que todavía nos sirven. Indudablemente, una lucha política colectiva necesita comunidad, la que está dada por algo que las personas comparten y que la mayoría de las veces necesita ser nombrado (en el sentido de lenguajeado). Esta mera acción, fija identidades y rápidamente las naturaliza; en palabras de Mouffe, se generan "efectos totalizantes" (1999:111), porque tal como ella enuncia, unas posiciones de sujeto toman preponderancia sobre otras. Ése es un problema que las postfeministas tienen a la hora de contestar al feminismo esencialista.

En mi análisis de la democracia radical, intentaré hacer equilibrio entre los filos del antiesencialismo y la necesidad de acción política, describiendo de qué manera el punto de vista planteado por Mouffe recuerda a los nuevos movimientos sociales, agrupados sobre la base de posiciones de sujeto (muchas veces contingente y temporal) y no sobre identidades unitarias y permanentes.

Lo que Mouffe intenta es mostrarnos la utilidad de una interpretación antiesencialista para la elaboración de una política feminista, al mismo tiempo que para el proyecto democrático radical. Lo especialmente revelador y desafiante del antiesencialismo es que aquellas diferencias por las cuales nos hemos preguntado durante muchos años (especialmente desde el feminismo) ya no tienen sentido. Mouffe (1999) provocativamente nos dice que en el caso del feminismo, el proyecto no consiste en relevar la categoría sexo o género como las unidades de análisis, sino más bien llegar a un punto en el cual éstas no tengan sentido.

Mouffe argumenta que con la puesta en cuestión que especialmente los psicoanálisis Freudiano y Lacaniano hacen del sujeto unitario, se producen dos efectos sobre la identidad: descentramiento y establecimiento de puntos nodales o fijaciones parciales (1999 y 2001). La diversidad, entonces, se vuelve un concepto clave, como lo es el concepto de equivalencia; la creación de una articulación equivalente entre grupos es la clave para canalizar la lucha política. De esta manera, lo que queda en relieve no es la esencia que une a las personas en una lucha, sino las contingencias y posiciones precarias que tienen en común, en un proceso de desplazamiento de los significados y descentramiento identitario constantes. 
Lo importante en este punto, es que la propuesta de Mouffe no es la disolución absoluta de las identidades a través del descentramiento perpetuo, sino el establecimiento de puntos nodales que estratégicamente pueden tomar la forma de sujetos colectivos. La diversidad, sin embargo, no debería ser llevada ad infinitum porque en un extremo está la completa atomización del ser humano, el individualismo aislado, el particularismo. Esto sería continuar la reducción que la sociedad de consumo especialmente, pero que también las teorías liberales "humanistas" han hecho de lo común (en el sentido de lo compartido) y que ha llevado a pensar el individuo no sólo como punto de partida sino también como punto de llegada, como lo que se debe alcanzar. Al respecto, Ernesto Laclau (2001) también advierte sobre los riesgos de poner al particularismo como el único principio válido, argumentando que esto no sólo generaría choques y antagonismos de valores, sino que podría ser ignorante de las relaciones de poder y subordinación ente los grupos.

Por otra parte, el problema con un proyecto democrático cualquiera, aún siendo, como lo propone Mouffe, radical, es precisamente el concepto de democracia el cual inevitablemente lleva en sí la semilla de una dictadura de las mayorías. La democracia es un proyecto universalista y liberal, muchas veces sustentado en el derecho (el cual no es un participante inocente) y que como tal hace problemático nuevamente el asunto de la diversidad, el poder y las posiciones de sujeto. Mouffe, sin embargo, reconoce que una comunidad política totalmente inclusiva no puede existir, lo que genera la pregunta de si finalmente es la democracia el modelo político deseable por excelencia o si al haber sido creada en una sociedad moderna, desde una filosofía predominantemente humanista, no estará condenada a nacer muerta. Esto sobre todo si lo que queremos es precisamente deconstruir lo natural, lo unitario y lo fijo, que están a la base de la modernidad y el humanismo. Mouffe propone ante estos dos problemas el vínculo de las personas a través de "su común identificación con una interpretación dada de un conjunto de valores ético-políticos" (Mouffe, 1999: 120); una forma de moral compartida, que en la lógica de un estado democrático, según yo lo veo, estaría indefectiblemente regulada por la ley.

Mouffe nos advierte que un proyecto construido sobre la base del principio de equivalencia democrática involucra necesariamente la creación de nuevas identidades, y habla también de la generación de una identidad política colectiva, lo que trasciende con mucho en complejidad, alcance y duración las meras fijaciones parciales y contingentes propuestas en un proyecto antiesencialista desde un sentido purista. La articulación hegemónica propuesta por Mouffe es, a mi juicio, una nueva forma de fijar algunos puntos de consenso sobre la base de una supuesta diversidad. Laclau (2001) defiende la posibilidad de una democracia en la no necesariedad del universalismo, sin embargo reconoce que los grupos luchan por universalizar sus particularismos; este último es el riesgo que considero inminente en esta propuesta.

Si bien es posible atisbar un estado parecido a una democracia radical en los nuevos movimientos sociales de resistencia global, un proyecto como el propuesto por Mouffe en una organización nacional, gubernamental u oficialista está probablemente destinado a reproducir las actuales estructuras democráticas. La única forma de funcionamiento de una democracia radical adivinable en ese contexto, parece ser el despliegue de estrategias liberales tales como la equidad de posiciones ${ }^{2}$ en los organismos de generación de regulaciones y leyes, lo que significaría, de todos modos, asumir la preponderancia de unas identidades sobre otras, no sólo inter- sino intra-individuos. Por otra parte,

\footnotetext{
${ }^{2}$ Traducida en cuoteos categoriales, como en los gabinetes ministeriales o congresos de Estados Unidos e Inglaterra.
} 
no sólo el consenso en cuanto a la generación de los valores ético-políticos, sino su aplicación y administración serían un problema de poder y equidad constantes. El modelo propuesto por Mouffe, sin embargo, puede tener una aplicación interesante a niveles micro (comunidades pequeñas y relativamente limitadas), de bajo nivel de formalidad y jerarquización, como los que son posibles observar dentro de los llamados nuevos movimientos sociales. Es verdad que todo reconocimiento de un nosotr@s implica la señalamiento de un ell@s (Mouffe, 1999), el "exterior constitutivo" (Mouffe, 2001: 37), pero la escala y nivel de comunidad de ese nosotr@s varía considerablemente la puesta en práctica de un proyecto basado en éticas comunes.

Aunque en la lectura de Mouffe ( $y$ de Laclau) puedo ver claramente el antiesencialismo como un punto teórico crucial, el proyecto democrático radical no me lo parece tanto. Hablo de sus potenciales efectos más que de las intenciones que lo animan. Las fijaciones parciales que se postulan como un modo de definir un nosotros (y por tanto una cierta hegemonía) como manera de canalizar las luchas políticas recuerda al concepto de "esencialismo estratégico" enunciado por Spivak (1988), quien critica el esencialismo en su aplicación, pero que sin embargo, siendo estratégicamente aplicado, como en el caso de los estudios subalternos en historiografía, puede resultar útil como herramienta de cambio y subversión.

Otro ejemplo interesante y que podría caber muy bien dentro del grupo de los nuevos movimientos sociales, es la categoría queer como elemento de contestación de la categorización, el universalismo y el unitarismo. Las teoría y práctica queer surgen como un movimiento anti-identitario a la vez que hiper-identitario (Preciado, 2002) lo que significa que responde al mismo tiempo a la necesidad de deconstruir y desafiar lo naturalizado y hegemónico de la sexualidad basada en el binario heterosexual/no-heterosexual (queriendo esto significar homosexual), y a la de identificarse como un grupo articulado, con ciertas fronteras. El colectivo queer (aunque puede haber varios) es un grupo de equivalencias, aplicando terminología de Mouffe y Laclau (1985), en donde las similitudes están relevadas por sobre las múltiples diferencias. Lo políticamente útil de lo queer es precisamente que no necesita identidades fijas ni naturales, que agrupa las necesidades de las personas en una identidad creada, contingente y con una irónica marca de aguda incorrección política. En adición y como producto de su no necesariedad, lo queer es una categoría que difícilmente puede ser externamente asignada; todas podríamos ser queer si así lo decidiéramos ${ }^{3}$, pero no es fácil a priori determinar si alguien es o no una queer. En realidad creo que esto responde a que finalmente lo queer no pretende ser una categoría ontológica sino política.

De la misma manera que la lucha política gay y lésbica en algunas partes ha devenido queer como una manera de visibilizar sectores en los márgenes, desnaturalizar la sexualidad y descentrar las identidades, los feminismos necesitan reconocer que la categoría de género y sexo no son las categorías centrales del mundo y las relaciones sociales, y que tampoco son las únicas que arrastran relaciones de poder desiguales e injustas. La fijación de la lucha política en un par de categorías no sólo las naturaliza, sino que tiende a recrear nuevas relaciones de subordinación y hegemonía en la invisibilización y universalización. Si las relaciones de dominación son lo que nos interesa, este argumento toma aún más fuerza, ya que el poder no se fija estáticamente en unas posiciones de

\footnotetext{
3 Indudablemente, no puede esta decisión ser de carácter meramente personal, sino que está necesariamente inscripta en una reflexión política y colectiva. En este sentido, y considerando la operación política involucrada, sí que la categoría queer está permanentemente abierta a nuevas formas de precariedades y resistencias.
} 
sujeto u otras, sino que, siguiendo una lógica Foucaultiana, lo hace fluidamente, de tal manera que en una misma persona y dependiendo de la contingencia y las múltiples posiciones en juego en un momento determinado, puede ser tanto oprimida como opresora. Sin embargo, la lucha por la deconstrucción social de la sexualidad y el género sigue siendo políticamente pertinente en muchos ámbitos, por lo que el feminismo todavía tiene mucho sentido como tal. Como Mouffe apunta, la lucha feminista no debe considerar como su fin la igualdad de un grupo homogéneo y unitario, sino mas bien "como una lucha en contra de las múltiples formas en que la categoría mujer se constituye como subordinación" (Mouffe, 1999: 26, énfasis original). Así también incluye la miríada de posiciones de sujeto que una mujer puede ocupar y que la sitúan también diferentemente respecto de otras. Un poco a diferencia de Mouffe, creo que el papel del feminismo no es sólo generar condiciones y reflexiones para crear la igualdad efectiva de las mujeres, sino que considero que la tradición feminista ha sido y puede ser todavía más en el futuro una fuente poderosa de reflexión para cualquier grupo en condiciones de opresión. Un ejemplo de esto es la reflexión de las teóricas feministas negras que usaron su plataforma feminista para desafiar el feminismo hegemónico y generar un discurso propio ${ }^{4}$, similar trabajo es el que están realizando las mujeres feministas de los enfoques post-coloniales. Además, aún cuando la puesta en duda del esencialismo ha servido para desnaturalizar la categoría mujer y con ello también desbaratar su carácter unitario, la generación de saberes desde posiciones de mujer diferenciales, como los estudios feministas postcoloniales, el pensamiento de las mujeres negras o latinoamericanas (por poner sólo algunos ejemplos) surgidos de identidades a mi juicio estratégicamente establecidas como puntos nodales, han sido y son clave para resignificar el poder y las relaciones de subordinación reproducidas al interior de movimientos inspirados por su afán de liberación. Poner en cuestión la feminidad no es suficiente; debemos poner en cuestión la masculinidad, la heterosexualidad y también categorías como la raza, la clase, las identidades asociadas al consumo y al trabajo, a las llamadas "etapas del desarrollo", etc.

Finalmente, el proyecto de una democracia radical es seductor, pero tiene sus alcances limitados a ciertas condiciones $\mathrm{y}$, ciertamente, no parece útil como continuadora de democracias como las que conocemos actualmente. El concepto de democracia radical tiene más sentido siendo un proyecto nómada, en el que los valores comunes sean continuamente reformulados y desnaturalizados y que sea profundamente crítica de sí misma. Aún las diversas posiciones que puede adoptar un sistema político democrático radical deben ser contingentes y precarias; en ese sentido, me adscribo al deseo-visión de Mouffe cuando dice que el bien común tendría que ser visto como algo "a lo cual debemos referirnos constantemente cuando actuamos como ciudadanos ${ }^{5}$, pero que nunca puede ser aprehendido" (Mouffe, 1999: 121). Al mismo tiempo, los conceptos de contingencia y precariedad plantean otra duda, y es si las asociaciones contingentes entre personas que luchan por un determinado objetivo político, no se volverían meras asociaciones temporales de conveniencia individual. Ante esto, queda el sabor de luchas desechables, algo así como compra tu lucha personalizada, a tu medida, una lucha que luego puede ser cambiada por otra mejor o más de moda. Esto último no sólo amenaza la profundidad de los movimientos y reivindicaciones, sino también la permanencia de sus resultados.

\footnotetext{
${ }^{4}$ Como ejemplo, ver Hooks (1984).

${ }^{5}$ En masculino en la traducción castellana.
} 


\section{Referencias}

Hooks, Bell. (1984). Feminist Theory, from Margin to Center. Boston: South end Press.

Laclau, Ernesto y Mouffe, Chantal. (1985). Hegemonía y Estrategia Socialista. Madrid: Siglo XXI.

Mouffe, Chantal. (1999). Feminismo, Ciudadanía y Política Democrática Radical. En Chantal Mouffe. (ed.). El Retorno de lo Político. Barcelona: Paidós.

Mouffe, Chantal. (2001). Algunes Observacions Sobre Política Feminista. Transversal. El Cos de les Idees, 36-41.

Preciado, Beatriz. (2002). Apuntes del curso "Teoría Queer, Performances de Género y Políticas Performativas". Universitat Autònoma de Barcelona.

Spivak, Gayatri. (1988). Los estudios Subalternos: La Deconstrucción de la Historiografía. En Dins Carbonell y Nuria Torras. (eds.). Feminismos Literarios. Madrid: Arco.

\section{Historia editorial}

Recibido: 12/09/05

Primerarevisión: 12/04/2006

Aceptado: $21 / 04 / 2006$

\section{Formato de citación}

Martínez, Soledad. (2006). Política democrática radical y feminismo. Athenea Digital, 9, 58-64. Disponible en http://antalya.uab.es/athenea/num9/martinez.pdf.

Soledad Martínez Labrín. Psicóloga, Universidad de Concepción, Chile. Master en estudios de género, University of Southampton, Inglaterra. Doctoranda en psicología social, Universitat Autònoma de Barcelona. Docente Universidad del Bío-Bío, Chile. 


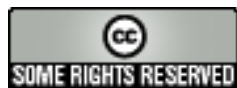

Este texto está protegido por una licencia Creative Commons.

Usted es libre de copiar, distribuir y comunicar públicamente la obra bajo las siguientes condiciones:

Reconocimiento: Debe reconocer y citar al autor original.

No comercial. No puede utilizar esta obra para fines comerciales.

Sin obras derivadas. No se puede alterar, transformar, o generar una obra derivada a partir de esta obra.

\section{$\underline{\text { Resumen de licencia }}$}

$\underline{\text { Texto completo de la licencia }}$ 